\title{
Inclusão social na era digital: Aspectos legais
}

\author{
Social inclusion in the digital Age: Legal aspects \\ Inclusión social en la era digital: Aspectos legales
}

Recebido: 16/06/2021 | Revisado: 25/06/2021 | Aceito: 29/06/2021 | Publicado: 13/07/2021

\author{
Nerivaldo Márcio Leone \\ ORCID: https://orcid.org/0000-0003-3275-1493 \\ Faculdade UNIVEM, Brasil \\ E-mail: neriplis@gmail.com \\ Jander Temístocles de Oliveira \\ ORCID: https://orcid.org/0000-0001-9890-1242 \\ Faculdade Ítalo, Brasil \\ E-mail: temistocles_jander@yahoo.com.br
}

\begin{abstract}
Resumo
Objetivo: promover a conscientização dos aplicadores do Direito a respeito da legislação que ampara a inclusão social digital. Método: realizamos uma revisão de literatura consultando a base de dados Google Escolar para o levantamento dos artigos com os descritores - inclusão digital legislação; inclusão social e digital. Conclusão: a exclusão digital, infelizmente, ainda hoje está presente na sociedade brasileira e, para promovermos a devida inclusão dessas pessoas precisamos pensar a educação nesse sentido, como o primeiro contato do cidadão com o mundo digital. Palavras-chave: Inclusão digital e legislação; Inclusão social e digital.
\end{abstract}

\begin{abstract}
Objective: to promote awareness among law enforcers regarding legislation that supports digital social inclusion. Method: we performed a literature review by consulting the Google Escolar database to survey the articles with the descriptors - digital inclusion legislation; social and digital inclusion. Conclusion: the digital divide, unfortunately, is still present in Brazilian society today, and in order to promote the proper inclusion of these people we need to think about education in this sense, as the citizen's first contact with the digital world.
\end{abstract}

Keywords: Digital inclusion legislation; Social and digital inclusion.

\section{Resumen}

Objetivo: sensibilizar a los agentes del orden sobre la legislación que apoya la inclusión social digital. Método: se realizó una revisión de la literatura mediante la consulta de la base de datos Google Escolar para la encuesta de artículos con descriptores - legislación de inclusión digital; inclusión social y digital. Conclusión: la exclusión digital, lamentablemente, todavía está presente en la sociedad brasileña hoy y, para promover la adecuada inclusión de estas personas, debemos pensar en la educación en este sentido, como el primer contacto del ciudadano con el mundo digital.

Palabras clave: Legislación de inclusión digital; Inclusión social y digital.

\section{Introdução}

A importância da inclusão social e digital ainda não se vê completamente materializada na Constituição Federal (1988) brasileira - não previu a Inclusão Digital inicialmente, havendo necessidade de emenda para tanto.

A fim de que haja a previsão de Inclusão Social e Digital foi aprovada a Emenda Constitucional nº0 (EC de 1990) que estabelece a nova redação deste artigo.

Conforme aponta Almeida (2015) as demandas sociais exigem cada vez mais rapidamente uma posição do direito no que concerne à tutela de direitos inerentes à inclusão digital.

Assim, nas palavras de Pierre Lévy, no que diz respeito ao uso do ciberespaço, que exige profunda reforma das mentalidades, dos modos de organização e dos hábitos políticos, temos a necessidade de:

[...] uma política voluntarista por parte dos poderes públicos, de coletividades locais, de associações de cidadãos e de grupos de empresários pode colocar o ciberespaço a serviço do desenvolvimento de regiões desfavorecidas, 
explorando ao máximo o seu potencial de inteligência coletiva: valorização das competências locais, organização das complementaridades entre recurso e projetos, trocas de saberes e experiências, redes de ajuda mútua, maior participação da população nas decisões políticas, abertura planetária para diversas formas de especialidades e de parceria etc. (Almeida, 2008, p. 185-186).

No que diz respeito à informação e ao conhecimento, o cenário atual é o de redes interligadas, que teve um crescimento visível a partir da década de 90 e aumentou exponencialmente nos últimos anos, com profunda repercussão nas atividades sociais, logo, demandando a previsão legal para regular essas interações sociais no cyberespaço.

A fim de que as inovações tecnológicas (inclusão social) cheguem e sejam disponibilizadas em todos os lugares há necessidade de previsão legal para tanto.

Dessa forma, a inclusão digital está no escopo da obrigação do Estado, devendo ser tratada no patamar dos direitos de primeira grandeza, provoque discordâncias com espeque no fato de que a inclusão social ainda não é uma realidade efetivada para muitos brasileiros (Almeida, 2015, p.31).

\section{Metodologia}

Para este Trabalho, realizamos uma revisão de literatura consultando a base de dados Google Escolar para o levantamento dos artigos com os descritores - inclusão digital legislação; inclusão social e digital; a fim de discutir os aspectos legais que norteiam a implementação da Inclusão Social Digital.

\section{Resultados e Discussão}

No intuito de promover a conscientização dos aplicadores do Direito a respeito da legislação que ampara a inclusão social digital desenvolvemos este trabalho revisando a literaturas encontrada.

Almeida (2015) analisou a inclusão digital como direito fundamental e destacou o termo "inclusão digital" como uma apropriação do termo "inclusão social".

Nessa perspectiva, olhando para os aspectos legais dessa inclusão social e digital

A inclusão digital é direito fundamental, mesmo que não expressamente positivado, a construção deste conceito não prescinde de uma boa argumentação jurídica e de uma teoria que deixe claro ao interlocutor a rigidez conceitual própria das grandes teses do direito. (Almeida, 215, p.10)

Para Demo (2005) existe ainda outro ponto a sublinhar, a discussão francesa sobre exclusão social, aparece frequentemente a ideia de que os pobres seriam, cada vez mais, descartáveis. Assim,

O analfabetismo digital vai se tornando, possivelmente, o pior de todos. Enquanto outras alfabetizações são já mero pressuposto, a alfabetização digital significa habilidade imprescindível para ler a realidade e dela dar minimamente conta, para ganhar a vida e, acima de tudo, ser alguma coisa na vida. (Demo, 2005, p.38)

A possível saída deste estado de exclusão social é aquele apontado por Barros et al. (2020) que destaca que a utilização das tecnologias vai muito além do uso do computador, já que hoje as tecnologias presentes desde o tablet até utensílios domésticos são "inteligentes”.

Temos, ainda, o ensino remoto ou EAD que enfaticamente aponta nessa direção que a educação assumiu os dois últimos anos, visto que em decorrência da Pandemia causada pelo novo Coronavírus (SARS-COV-2), doença que assola o país desde março de 2020, precisamos reconhecer a validade e importância dessa nova modalidade de ensino - uma poderosa aliada da inclusão social digital (III Seminário, 2020).

Barros et al. (2020) constatou que o termo "envelhecimento ativo" se refere não apenas ao estar fisicamente ativo, ou 
à força de trabalho, mas também a uma participação contínua nas questões sociais, económicas, culturais, espirituais e civis, tal como referem Malanowski, et al. (2008, p. 13).

Nesse sentido, o envelhecimento ativo foi adotado no fim da década de 90 e fundamentado pelo envelhecimento como um processo de oportunidades para a saúde e qualidade de vida (BARROS et al. 2008).

Demo (2005) nos informa que neste debate, existe ainda outro ponto a sublinhar - a pobreza não é mau jeito do mercado, mera carência material, casualidade, mas produto histórico-dialético que compromete o processo de inclusão social e digita.

Outra observação que Demo (2005) faz é a de que em relação aos alunos, a discriminação digital pode ser menos de ordem material de acesso a equipamentos, por exemplo, do que a pobreza do ambiente escolar, cuja linguagem não se coaduna com os desafios digitais fora da escola.

Almeida (2015) reconhece que o Direito pode dar atenção à inclusão digital, mas não pode ser construído a partir de imposições que ofendam garantias jurídicas e nem a partir de teorias que não se adequam ao modelo de direito que vem se afirmando nos últimos anos e que se faz necessária uma teoria que justifique a inclusão digital como direito, mais ainda, como um direito fundamental.

Conforme Carneiro et al. (2020) o Ministério da Educação (MEC) a Portaria $n^{\circ}$ 343. ambos solicitaram o distanciamento social e paralisação de encontros presenciais devido à pandemia do COVID-19. Assim, atendendo a todas essas recomendações, as atividades acadêmicas foram suspensas pelas Instituições de Ensino Superior (IES), e dessa forma, a interrupção das aulas presenciais revelou uma realidade desafiadora: a dificuldade de acesso a recursos tecnológicos por parte dos discentes e a falta de equipamentos para docentes.

Borges, Bandeira e Corrêa (2020) realizaram um ensaio acerca da inclusão da

pessoa com deficiência diante da inviabilidade de encontros presenciais cujo objetivo foi analisar as condições de atuação de estudantes e professores por meio de Tecnologias Digitais de Informação e Comunicação (TDIC) e constataram que devido a especificidade exigida, o não domínio dos integrantes nos programas digitais adotados desafiam os sujeitos envolvidos durante todo o percurso, chegando à conclusão de que mesmo garantido na legislação o direito à educação e aos recursos tecnológicos para pessoas com deficiência, na realidade apresenta-se uma baixa inclusão digital.

É relevante destacar o parecer do Conselho Nacional de Educação CNE/CP No5, de 28 de abril de 2020 (BRASIL, 2020), que apresenta medidas para a realização de atividades pedagógicas não presenciais. Dentre elas, destaca-se a listagem de meios não presenciais que podem ser utilizados (plataformas digitais, plataformas virtuais, mídias sociais, videoaulas, vídeos educativos, programas de televisão, entre outros) e a indicação dos familiares como mediadores para as atividades escolares. A chamada Lei Brasileira de Inclusão da Pessoa com Deficiência, Lei 13.146/2015, de 6 de julho de 2015, instituída no Governo Dilma Roussef, reforça que a Educação de qualidade é um direito de todos, no entanto as condições de infraestrutura das instituições escolares, a formação específica para os docentes que atuam nessa modalidade, as condições socioeconômicas do familiares desses estudantes, não viabilizam o cumprimento de tal legislação. (Borges, Bandeira \& Corrêa, 2020, p.104)

Ainda no escopo de inclusão, Silva, Colling, e Mueller (2020) desenvolveram um questionário para coleta de dados em sua pesquisa exploratória a fim de coletar dados de fevereiro a outubro de 2020 entrevistando profissionais da área de telecomunicações da região do extremo oeste de Santa Catarina, passando a entrevistar os sujeitos de forma remota devido à pandemia SARS-COVID-19, enviando o referido questionário para grupos de agricultores via WhatsApp. Ao questionarem os produtores rurais sobre a receptividade da Internet em suas casas,

$\mathrm{Na}$ totalidade das respostas, obtivemos $66,7 \%$ das respostas afirmando que havia muito menos agilidade nas comunicações, seguido por 53,3\% afirmando que possuíam mais tempo disponível com a família e em torno de $43 \%$ confirmaram a falta de informações a nível mundial e a disponibilidade de maior tempo para ocupação com as tarefas 
diárias que correspondeu a 40\%. (Silva, Colling, \& Mueller, 2020, p.3).

Assim, Silva, Colling, e Mueller (2020) dando continuidade às perguntas e analisando as respostas registradas puderam constatar que últimos 10 a 14 anos tiveram uma evolução significativa na expansão dos sinais de Internet oferecidos ao produtor rural.

Bunduki e Alencar (2021) abordaram as dificuldades enfrentadas pelo direito à educação, sob o prisma da qualidade e universalização do ensino, no atual cenário de isolamento social e pandemia realizando uma análise sobre o Ensino Remoto Emergencial, que se baseia no uso de sistemas virtuais, se realisticamente é compatível com os princípios postos pela legislação brasileira atual, destacando nesse cenário, as políticas públicas voltadas à inclusão digital de alunos, à qualificação de professores para a atuação em ambientes virtuais, e à distribuição de materiais físicos. Durante este percurso, puderam verificar que a Constituição Federal de 1988 individualiza a educação como bem jurídico, e a insere nos conjuntos de direitos sociais, e que

a Constituição, a Lei de Diretrizes e Bases da Educacional Nacional de 1996, o Plano Nacional de Educação de 2014 e o ECA regulamentam o direito à educação em uníssono, no que toca à garantia dos princípios de universalização e qualidade do ensino. (Bunduki \& Alencar, 2021, p.242)

Assegurar o cumprimento da legislação em sua implementação não representa o fim do processo, já que há a necessidade de acompanhar o bom uso dessas garantias conforme Silveira (2021) se materializa na liberdade de expressão, responsabilidades, deveres e limites. Nesse sentido, enfoca o aspecto de deveres e limites que tal liberdade impõe, sendo o único autor referenciado por esta revisão que se deteve a analisar esse aspecto fundamental que diz respeito à responsabilização e limites que tal tecnologia impõe:

Analisa-se a liberdade de expressão e sua natureza principiológica e infere-se que, por vezes, ela se encontrará em conflito com outros princípios constitucionais. Explora-se os diferentes dispositivos de proteção da livre manifestação de pensamento, destacando, ao final, a sua primordial relevância na construção do conhecimento e da democracia. O terceiro capítulo explora a importância dos meios digitais para o cenário político atual e como os indivíduos ultrapassam os limites para beneficiar o seu lado da política. Com isso traz quais são os limites da liberdade de expressão e explicitando os motivos pelos quais ela não engloba a fake news. Adiante, o hate speech na internet será abordado, com o objetivo de conceituar e ter uma visão jurídica acerca deste ato praticado na internet, o discurso de ódio se configura como tal por ultrapassar o limite do direito à liberdade de expressão. (Silveira, 2021, p.9)

Pereira e Pereira (2021) lançam olhar sobre o cenário do Brasil em face da Pandemia SARS-COVID-19 e a inépcia do Presidente da República para tratar conjuntamente da crise de saúde e assegurar o uso saudável das redes sociais e internet no processo de inclusão e ensino, destacando que

A miséria política a qual se refere tem na presidência da República sua expressão maior: um perverso populista, genocida e negacionista. (...) Não é demais lembrarmos que o Brasil apresenta hoje o pior quadro mundial de resposta à COVID. (...) Para evidenciar esse cenário, podemos pensar em duas importantes ações tomadas pelos Governo Federal, que impactam diretamente na ampliação das disparidades sociais. Por um lado, a manutenção do semestre letivo na modalidade remota e, derivada do primeiro, a insistência em realizar no momento mais agudo da chamada "segunda onda da pandemia" os exames nacionais de acesso ao ensino superior, em nome de exigências burocráticas. (Pereira \& Pereira, 2021, pp. 2-4).

Schossler, Medeiros, Paprosqui, Germani e Folmer (2021) lançam seu olhar para a inclusão digital em escolas rurais ou do campo indicando que o ensino mediado pelas Tecnologias da Informação e Comunicação (TICs) pode promover 
mudanças nos papéis de todos os envolvidos no processo educacional, trazendo mudanças de representações e formando pessoas, não apenas para os saberes escolares, mas para a formação de cidadãos mais críticos no processo de construção de uma sociedade mais igualitária.

O olhar de Assunção e Andrade Oliveira (2021) se volta para a questão do acesso à biblioteca digital, aspecto também muito importante para inclusão de deficientes, dada a realidade que se impõe pela presença de discentes que se declaram com deficiência no ensino superior sinalizando para que as bibliotecas universitárias avaliem os seus produtos e serviços na perspectiva da acessibilidade e inclusão.

\section{Considerações Finais}

A conclusão a que chegamos foi a de que a exclusão digital, infelizmente, ainda hoje está presente na sociedade brasileira e, para promovermos a devida inclusão dessas pessoas precisamos pensar a educação nesse sentido, como o primeiro contato do cidadão com o mundo digitalizado.

Observamos, ainda, a necessidade de legislação específica sobre essa questão em particular, isto é, a inclusão social e digital precisa ser regulamentada em cada ente da federação.

Por fim e não menos importante, tomarmos consciência de que tudo precisa sair da esfera da legislação e ser devidamente implementado pelos Estados, Municípios e União pois foi necessária uma pandemia para que a realidade digital se impusesse e docentes saíssem do modo analógico e admitissem que não se atualizaram para esta realidade cada vez mais presente e desafiadora.

\section{Agradecimentos}

Aos pareceristas por sua contribuição e sugestões que foram acatadas com mútuo apreço.

\section{Referências}

Almeida, L. G. de. A inclusão digital como direito fundamental não expresso. 2015. Dissertação de Mestrado - Programa de Mestrado em Ciência Jurídica Universidade Estadual do Norte do Paraná.

Assunção Costa, M., \& Andrade Oliveira, D. (2021). Usuários da informação com deficiência e o papel das bibliotecas universitárias. Ciência da Informação em Revista, 8(1), 95-118. https://doi.org/10.28998/cirev.2021v8n1f

Barros, D. M. V. et al. Universidades Seniores Em Portugal E O Uso Das Tecnologias Digitais: inclusão digital e social. Educação em Foco, 23, 446-461

Borges, L., Bandeira, D. P., \& Corrêa, S. B. C. C. Inclusão Digital E O Precário Ensino Remoto Em Tempos De Pandemia. III Seminário Diálogos sobre EAD. Belo Horizonte/MG Dezembro 2020.

Brasil. (2007). Decreto $n^{\circ}$ 6.300. Dispõe sobre o Programa Nacional de Tecnologia Educacional - ProInfo. Diário Oficial da República Federativa do Brasil. Brasília, DF, 13 dez. 2007. http://www.planalto.gov.br/ccivil_03/_Ato20072010/2007/Decreto/D6300.htm

Bunduki, A., \& de Alencar, D. (2021). Ensino Remoto Emergencial E Os Entraves Ao Direito À Educação. Revista Da Defensoria PúBlica Do Estado De SãO Paulo, 2(2), 225-248.

Carneiro, L. de A., Rodrigues, W., França, G., \& Prata, D. N. Use of technologies in Brazilian public higher education in times of pandemic COVID-19. Research, Society and Development, 9 , e267985485, 10.33448/rsd-v9i8.5485.

Demo, P. Inclusão digital: cada vez mais no centro da inclusão social. Inclusão Social, 1, 36-38.

Levi, P. Cibercultura. Trad. de Carlos Irineu da Costa. Editora 34, 2008.

Olegário, P. T., \& Gallo, F. Banco Postal e Uso do Território no Brasil: da inclusão financeira à inclusão digital. Geografia. 30, 23 - 41, 10.5433/24471747.2021v30n1p23

Pereira, M. G., \& Pereira, D. S. Dos Limites Da Educação Remota: O Caso Do Brasil Na Pandemia. (2021) SIMPOSIO: Acceso a una educación básica inclusiva, equitativa y de calidad.

Silva, J. M, Colling, J., \& Mueller, S. Inclusão Digital no campo: implantação e expansão da Internet no meio rural da região extremo oeste catarinense. XVII Congresso Latino-Americano de Software Livre e Tecnologias Abertas. Latinoware, 2020. 
Research, Society and Development, v. 10, n. 8, e30310817261, 2021

(CC BY 4.0) | ISSN 2525-3409 | DOI: http://dx.doi.org/10.33448/rsd-v10i8.17261

Silveira, G. M. L. M. Direito Digital E Os Desafios Da Liberdade De Expressão. (2021) Trabalho de Conclusão de Curso. PUC Goiás https://repositorio.pucgoias.edu.br/jspui/handle/123456789/1644

Schossler, A. B., Medeiros, L. M., Paprosqui, J., Germani, A. R. M., \& Folmer, I. (2021). Digital inclusion in field schools. Research, Society and Development, 10(5), e44710514819. https://doi.org/10.33448/rsd-v10i5.14819 